\title{
Capsule Commentary on Grant, et al., Exercise as a Vital Sign: A Quasi-Experimental Analysis of a Health System Intervention to Collect Patient-Reported Exercise Levels
}

\author{
Steven R. Simon, MD, MPH \\ VA Boston Healthcare System, Boston, MA, USA.
}

$\mathrm{J}$ Gen Intern Med 29(7):1059

DOI: $10.1007 / \mathrm{s} 11606-013-2762-0$

(c) Society of General Internal Medicine 2014

$\mathrm{F}$ ive decades ago, President Eisenhower launched, and President Kennedy greatly expanded and popularized, the President's Council on Physical Fitness, ${ }^{1}$ jumpstarting what later became "the fitness craze" of the 1980 s. $^{2}$ Despite our apparent obsession with fitness, only one in five Americans achieves recommended levels of aerobic and muscle-strengthening physical activity, ${ }^{3}$ leading to obesity, diabetes and other comorbidities. To counter this inertia, Grant et al. at Kaiser Northern California report the results of Exercise as a Vital Sign (EVS), ${ }^{4}$ a primary care-based intervention aligned with the Chronic Care Model, designed to ascertain patients' physical fitness levels and facilitate counseling and referral to tailored programs when appropriate.

In an excellent example of not allowing perfect to be the enemy of the good, the authors employed a quasiexperimental design to capitalize on a health system's rollout of EVS. This intervention empowered medical assistants to query primary care patients about their current activity level and to enter the data into a structured field in the electronic health record, adjacent to weight and blood pressure, easily visible to the clinician. In less than 2 years, this low-cost systemlevel intervention led to small but statistically significant-and clinically significant, at least at a population level-improvements in clinical documentation of exercise, patients' report of physician counseling on activity, weight loss and HbAlc changes in patients with diabetes. Whether the improved outcomes resulted from the physician counseling or from the medical assistants asking about exercise, juxtaposed with measurements of weight and blood pressure, needs further study.
The authors conclude that EVS may serve as a catalyst for primary care counseling to lead to referral for behavioral health intervention, presumably some form of health-care supervised or endorsed physical activity program. While this approach deserves consideration, other strategies would include, for example, enhancing the clinicians' own ability to deliver effective exercise counseling through education and training in motivational interviewing. Moreover, additional approaches that target and engage patients directly, such as mobile health (e.g., via texting or smartphone applications) and other automated technologies, ${ }^{5}$ could be linked to EVS to enhance the capacity of primary care to motivate physical activity.

Conflict of Interest: The author has no conflict with any of the material in this manuscript.

Corresponding Author: Steven R. Simon, MD, MPH; VA Boston Healthcare System, Boston, MA O2130, USA (e-mail: Steven.simon2@va.gov).

\section{REFERENCES}

1. President's Council on Fitness, Sports \& Nutrition. Available at: [http:// www.fitness.gov/about-pcfsn/our-history/]. Last accessed December 20, 2014.

2. Reed J. America shapes up. Cover Story Time. 1981;2:94-106.

3. Harris CD, Watson KB, Carlson SA, Fulton JE, Dorn JM, Elam-Evans L. Adult participation in aerobic and muscle-strengthening physical activities-United States, 2011. Morb Mortal Wkly Rep. 2013;62(17):326-330.

4. Grant RW, Schmittdiel JA, Neugebauer RS, Uratsu CS, Sternfeld B. Exercise as a vital sign: a quasi-experimental analysis of a health system intervention to collect patient-reported exercise levels. J Gen Intern Med. 2013. doi:10.1007/s11606-013-2693-9.

5. Bickmore TW, Silliman RA, Nelson K, Cheng DM, Winter M, Henault L, Paasche-Orlow MK. A randomized controlled trial of an automated exercise coach for older adults. J Am Geriatr Soc. 2013;61(10):16761683. 